\title{
The Developmental Significance of Adolescent Romantic Relationships: Parent and Peer Predictors of Engagement and Quality at Age 15
}

\author{
Glenn I. Roisman · Cathryn Booth-LaForce • \\ Elizabeth Cauffman · Susan Spieker • \\ The NICHD Early Child Care Research Network
}

Received: 12 October 2008/Accepted: 2 December 2008/Published online: 18 December 2008

(c) The Author(s) 2008. This article is published with open access at Springerlink.com

\begin{abstract}
From a longitudinal sample ( $n=957 ; 49.9 \%$ male; $77.3 \%$ White/non-Hispanic) of participants studied from infancy through age 15 , adolescents' depth of engagement in, and quality of romantic relationships were predicted from early and contemporaneous parent-child interactive quality and peer social competence. High quality maternal parenting and peer experiences prior to and during adolescence tended to be negatively associated with the depth of engagement in this domain for the full sample, yet positively associated with the quality of adolescents' romantic relationships for the sub-set of individuals currently dating at age 15 . Results reconcile contrasting views of the origins of romantic relationship engagement and quality and the positive versus negative
\end{abstract}

This study is directed by a Steering Committee and supported by NICHD through a cooperative agreement (U10), which calls for scientific collaboration between the grantees and the NICHD staff. The content is solely the responsibility of the named authors and does not necessarily represent the official views of the Eunice Kennedy Shriver National Institute of Child Health and Human Development, the National Institutes of Health, or individual members of the Network.

\section{G. I. Roisman ( $\square)$}

Department of Psychology, University of Illinois at UrbanaChampaign, 603 East Daniel Street, Champaign, IL 61820, USA

e-mail: roisman@uiuc.edu

C. Booth-LaForce $\cdot$ S. Spieker

University of Washington, Seattle, WA, USA

E. Cauffman

Department of Psychology and Social Behavior,

University of California, Irvine, CA, USA

The NICHD Early Child Care Research Network Bethesda, MD, USA developmental salience of romantic relationships in adolescence.

Keywords Romantic relationships - Adolescence . Peer competence $\cdot$ Parenting $\cdot$ Longitudinal

\section{Introduction}

In recent years, adolescence scholars (Collins 2003; Furman et al. 1999) have made a compelling case that adolescent romantic relationships represent an important context of human development, in particular by emphasizing that these relationships likely integrate the functions of, and are in part organized by, prior and contemporaneous experiences with parents and peers. In apparent contrast, however, other evidence has called into question whether such early romantic relationships-though quite normative in this age period-should be considered salient developmental tasks in adolescence, in part because (a) competence in this domain may not have long-term predictive significance for adaptation in adulthood (Roisman et al. 2004) and (b) precocious engagement in this domain may actually undermine development (Davies and Windle 2000; Neemann et al. 1995). The present study attempts to reconcile these two lines of research by examining whether high-quality parenting and peer experiences prior to and during adolescence were negatively associated with the depth of romantic relationship engagement (e.g., number of serious relationships; sexual experience) for a cohort tracked from infancy to age 15 . Then, for the subsample with a current romantic involvement at the time of the age 15 survey, we examined whether high-quality parenting and peer experiences prior to and during adolescence were positively associated with romantic relationship quality. 
Most theories of the development of romantic relationships have focused on parents' influence on adolescents (Connolly et al. 2000). According to attachment theorists, the attachment behavioral system provides the foundation for the attachment, caretaking, and sexual behavior systems operating in romantic relationships (Furman and Wehner 1994). Early experiences in attachment relationships affect individuals' ability to form affectional bonds as well as the quality of these bonds. Hazan and Shaver (1987) proposed that representations of parent-child relationships influence representations of romantic relationships because these relationships serve similar attachment functions, suggesting continuities between experiences with primary caregivers and the quality of later romantic attachments.

Although some research has shown links between childparent attachment and romantic relationships, these studies frequently have focused on late adolescents and young adults (e.g., Collins et al. 2002; Roisman et al. 2005, 2001; Scharf and Mayseless 2001), perhaps because, until recently, it was assumed that romantic relationships in adolescence were of little developmental significance (Collins 2003). In one exception, Engles et al. (2001) showed that attachment to parents was related to 15- to 18 -year-old adolescents' social skills, which in turn were associated with adolescents' friendship and romantic relationship competence. Other research indicates that negative emotionality (e.g., anger, ambivalence) in parent-adolescent dyads is predictive of poor quality interactions with romantic partners in late adolescence (Kim and Capaldi 2004). Thus, there is some evidence that individuals with more supportive experiences with parents also tend to have higher quality romantic relationships in adolescence.

An alternative view is that adolescents' romantic relationships, particularly those that occur before late adolescence, are more closely aligned with their relationships with close friends and other peers than with their relationships, past and present, with parents (Connolly et al. 2000; Furman 1999). Early and middle adolescents' romantic relationships are less intimate than later romantic relationships and primarily involve the affiliative and sexual systems rather than the attachment and caregiving systems (Connolly and Johnson 1996; Furman 1999; Furman and Wehner 1994). Furthermore, romantic relationships are egalitarian and develop within the peer network, unlike child-parent attachment relationships (Furman and Wehner 1994). Indeed, early on, Sullivan (1953) proposed that the capacity for intimacy first develops during pre-adolescence in same-sex friendships. According to Sullivan, once puberty begins, heterosexual adolescents begin to desire and seek intimacy in oppositesex romantic relationships, transferring what they have learned in same-sex friendships to opposite-sex romantic relationships.
There is some empirical evidence of associations between the qualities of peer and romantic relationships (Connolly et al. 2000; Connolly and Johnson 1996; Furman and Wehner 1994; Furman et al. 2002; Shulman et al. 1997). In addition, Furman and colleagues have stated that current evidence indicates that links between supportive characteristics of parental and romantic relationships are weaker than those between friend and romantic relationships in adolescence, yet virtually no study of adolescents' romantic relationships has included data on parent-child and friend relationships beginning in infancy and early childhood, respectively (Furman 1999; Furman et al. 2002; cf. Collins and Sroufe 1999).

The current study aims to address this gap in the literature using prospective, longitudinal data drawn from a cohort of over 1,000 youth tracked from infancy through age 15 as part of the National Institute of Child Health and Human Development Study of Early Child Care and Youth Development (NICHD SECCYD). Specifically, we drew on outcome data on romantic relationship engagement and quality (the latter for the subset currently involved in a romantic relationship) from the age 15 assessment of this cohort, as well as observational data on maternal sensitivity and mother-reports of participants' peer competence from childhood through mid-adolescence.

\section{Hypotheses}

Following from the results of studies conducted to date on adolescent romantic relationships reviewed above, we expected that both parent-child and peer relationships in childhood and adolescence are likely to be correlated with the quality of adolescents' romantic relationships at age 15, such that supportive experiences with parents and peers is reflected in higher quality romantic relationships during adolescence. However, in line with recent theory and evidence that romantic relationships represent emerging (rather than already salient) tasks of development in adolescence (Roisman et al. 2004), we hypothesized (a) that high-quality experiences with parents and peers are most likely to be reflected in higher-quality romantic relationships for the sub-set of adolescents who engage in them, yet (b) negatively associated with indicators of intense engagement in this domain. This latter hypothesis is consistent with other empirical evidence that family experiences can, in part, influence the likelihood that adolescents engage in risky sexual behavior (Coley and Chase-Lansdale 1998; Ellis et al. 2003) and longstanding theoretical arguments that adolescence reflects a period focused on the development of identity, only after which (in adulthood) does intimacy (with romantic partners) emerge as a central theme of development (Erikson 1968). 


\section{Method}

Participants

Participants were enrolled in the NICHD SECCYD, a prospective longitudinal study conducted at 10 research sites across the US (Charlottesville, VA; Irvine, CA; Lawrence, KS; Little Rock, AR; Madison, WI; Morganton, NC; Philadelphia, PA; Pittsburgh, PA; Seattle, WA; and Wellesley, MA). During selected 24-h sampling periods 8,986 women who gave birth were screened, and 5,416 met the eligibility criteria for the study. Families were excluded if the mother was younger than 18 years of age; the family planned to move; there was a multiple birth; the infant had a known disability or remained in the hospital more than 7 days; the mother acknowledged substance abuse; the mother did not speak English; or the mother lived more than an hour from the laboratory site or in an extremely unsafe neighborhood as determined by local police. From that group, 1,364 families became study participants upon completing a home interview when their infants were 1 month old. The recruited sample consisted of $52 \%$ boys, $24 \%$ children of color, $11 \%$ mothers not completing high school, and 14\% single-parent families. Additional details about recruitment and selection procedures are available in prior publications from the study (see NICHD Early Child Care Research Network 2005) and from the study web site (http://secc.rti.org/).

The analysis sample in the present report comprised 957 (49.9\% male) of the 1,364 children, due to attrition and missing data (note that although $n=957$ is the sub-sample of participants at age 15 who completed the measure of romantic relationship involvement, $n=213$ indicated a current romantic relationship and completed questions related to quality $-n$ s fluctuate further as a function of missing data from earlier assessments). Participants included in the $n=957$ analysis sample were primarily nonHispanic White (77.3\%), their mothers had a mean of 14.5 $(\mathrm{SD}=2.4)$ years of education when participants were 1 month old, and their families had a mean income-toneeds ratio (from 1 month through 15 years) of 4.0 $(\mathrm{SD}=3.0)$.

\section{Procedure}

Children were followed from birth through age 15 . Assessments occurred when the children were 1, 6, 15, 24, 36 and 54 months old; when they were in kindergarten and Grades 1, 2, 3, 4, 5, and 6; and at age 15 (data were gathered from participants at home, in the laboratory, at school, and via regular phone calls by trained personnel from the ten study sites that were centrally trained and certified to conduct each assessment). The following sections describe the specific measures used in the present analyses and the time points of administration. Additional details about all data collection procedures, psychometric properties of the instruments, and descriptions of how composites were derived and constructed can be found in the study's Manuals of Operation and Instrument Documentation (http://secc.rti.org).

\section{Measures}

\section{Demographic Characteristics}

Child gender and maternal education level were obtained by maternal report at 1 month. Family income was reported by mothers at each major data collection point (1 month through age 15) and converted to an income-to-needs ratio by dividing total family income by the US Census-based poverty-level income for that family size. Ratios used in analyses were averaged from data obtained at 1 month through 15 years. Child race/ethnicity was coded as $1=$ White/non-Hispanic, $0=$ all others represented in the cohort (Hispanic, African American, Asian, Native American, biracial, or other).

\section{Maternal Sensitivity}

Earlier Maternal Sensitivity Our measure of earlier maternal sensitivity was calculated from mothers' behavior during a videotaped interaction between mother and child under semi-structured conditions at 6, 15, 24, 36, 54 months, and grades 1, 3, and 5 (NICHD Early Child Care Research Network 1998, 2002). A composite score of maternal sensitivity was created at each age from coding of the videotapes for developmentally appropriate indicators of sensitivity. These composites were transformed to the same scale and averaged from 6 months to Grade 5 (standardized $\alpha=.83$ ).

Contemporaneous Maternal Sensitivity Contemporaneous sensitivity was assessed at age 15, via coding of a video-recorded 8-min home discussion of one or two areas of disagreement between the adolescent and mother (e.g., chores, homework, money), selected by the adolescent (this variable was standardized for analyses). Seven-point rating scales of the interaction were used, with higher scores indicting higher levels of sensitivity (M. T. Owen et al., 2006, Unpublished manuscript), based on adaptations of the more micro-analytic coding systems of Allen and his colleagues (J. P. Allen et al., 2003, Unpublished manuscript) and coding systems used at earlier ages in the NICHD SECCYD (e.g., M. T. Owen et al., 2000, Unpublished manuscript). Interrater reliability (intraclass correlation) was .86 . 


\section{Peer Competence}

Earlier Peer Competence We assessed earlier peer competence using mother reports on an a priori, internally consistent peer competence sub-scale derived from the Social Skills Rating System (SSRS; Gresham and Elliott 1990) when children were age 54 months, in kindergarten, and grades 1, 3, 4, 5, and 6. (Standardized alphas for these scales at each assessment point ranged from .70 to .80; mean $=.75$ ). These scales were, in turn, averaged to form a single measure of early peer competence (standardized $\alpha=.91)$

Contemporaneous Peer Competence At age 15, we assessed contemporaneous peer competence using the $z$-score of the same sub-scale (i.e., peer competence) of the SSRS (standardized $\alpha=.81$ ), again as reported by mothers, with higher scores indicating higher levels of peer competence. (Note that maternal reports were used at age 15 to maintain consistency with the earlier assessments).

\section{Romantic Relationship Quality and Engagement at Age 15}

Romantic Relationship Quality Romantic relationship quality was measured using items from the Network of Relationships Inventory (NRI; Furman 1996) pertinent to romantic relationships that were completed by the participating adolescents at age 15. Specifically, this slightly modified 29-item measure resulted in ten a priori scales: companionship, conflict, instrumental aid, intimacy, nurturance, affection, admiration, reliable alliance, antagonism, and criticism (the internal consistencies of these scales ranged from .61 to $.90 ;$ mean $=.81)$. In order to further reduce the number of dependent measures of quality, we subjected these NRI sub-scales to a Principal Components Analysis, which yielded evidence for two components: (a) positive qualities (i.e., companionship, instrumental aid, intimacy, nurturance, affection, admiration, reliable alliance; standardized $\alpha=.91$ ) and (b) negative qualities (i.e., conflict, antagonism, and criticism; standardized $\alpha=.89$ ). Note that only participants currently in a romantic relationship at the age 15 assessment completed the NRI.

Depth of Romantic Engagement The entire age-15 cohort completed questions about their depth of engagement in the romantic domain. For the current study we used the four indicators derived from a set of descriptive items, in addition to a measure of sexual behavior, to assess depth of romantic engagement. More specifically, the four descriptive indicators included (a) a Guttman-like composite scale of dating experience based on the average of answers given to five yes/no questions (I only hang out with same-sex friends [reversed], I go to activities with boys and girls present, I go to dances with boys and girls present, I go out at night in group with boys and girls, I go out on dates-but with a group, and I go out on dates-just the two of us), (b) Longest romantic relationship (in days), (c) Number of serious romantic relationships, and (d) the response to the question: "Have you ever been deeply in love?" To assess sexual behavior, participants were also asked how many times they had ever had oral sex (recoded either to $0=$ never or $1=$ one or more times) or engaged in sexual intercourse (recoded either to $0=$ never or $1=$ one or more times) with higher scores indicative of more sexual involvement. The two sexual behavior indicators were averaged.

\section{Results}

\section{Analytic Plan}

Data were analyzed in two steps. First, we provide descriptive information in order to characterize (a) involvement in romantic relationships at age 15 , as reflected in dating, sexual, and romantic engagement for the full cohort and (b) the perceived quality of participants' romantic relationships for the sub-set of individuals who were currently dating. Second, we examined early and contemporaneous parenting and peer competence as predictors of romantic engagement (for the entire sample) and perceived quality (for the currently dating sub-group). We present both correlational data as well as regressions where all independent variables were simultaneously entered as predictors of each romantic outcome at age 15. A series of follow-up regressions were conducted and reported that also include demographic covariates (i.e., child sex, child ethnicity, maternal education, and family income-to-needs through age 15) as predictors in order to examine how robust effects of sensitivity and peer competence were after accounting for potential confounds. Note finally that many of the analyses reported here had high levels of statistical power to detect statistically significant effects-even for correlations small in absolute magnitude. As such, consistent with Cohen's (1988) recommendations, we viewed correlations smaller than $r=.10$ as of "trivial" magnitude.

\section{Descriptive Data}

Descriptive data on all romantic relationship dependent measures are presented in Table 1. Measures of engagement in romantic relationships completed by the full cohort demonstrate that, with just a few exceptions focused on dating experience, adolescents were not engaging in high levels of romantic involvement at age 15. For example, 
Table 1 Descriptive statistics for romantic relationship outcomes

\begin{tabular}{|c|c|c|c|c|c|}
\hline Variable & $n$ & $M$ & SD & Min & $\operatorname{Max}$ \\
\hline \multicolumn{6}{|l|}{ Romantic relationship engagement } \\
\hline 1. Only hang out with same-sex friends & 957 & $11.3 \%$ & - & - & - \\
\hline 2. Go to activities with boys and girls present & 956 & $96.7 \%$ & - & - & - \\
\hline 3. Go to dances with boys and girls present & 950 & $91.9 \%$ & - & - & - \\
\hline 4. Go out at night in group with boys and girls & 949 & $69.3 \%$ & - & - & - \\
\hline 5. Go out on dates, but with a group & 935 & $45.3 \%$ & - & - & - \\
\hline 6. Go out on dates, just the two of us & 936 & $46.9 \%$ & - & - & - \\
\hline Dating experience (mean of 1-6) & 957 & .73 & .22 & 0 & 1 \\
\hline Longest relationship (in days) & 828 & 215.92 & 289.90 & 0 & 2,555 \\
\hline Number of serious relationships & 939 & 1.24 & 2.01 & 0 & 25 \\
\hline Sexual experience & 951 & 0.22 & 0.56 & 0 & 2 \\
\hline Ever deeply in love? & 943 & $34.5 \%$ & - & - & - \\
\hline \multicolumn{6}{|l|}{ Romantic relationship quality } \\
\hline Positive relationship quality & 213 & 10.52 & 2.14 & 2.86 & 14.29 \\
\hline Negative relationship quality & 212 & 4.27 & 1.95 & 3.00 & 15.00 \\
\hline
\end{tabular}

Note: The first six indicators under romantic relationship engagement were averaged to form the dating experience composite (the first item was reversed prior to aggregation)

whereas a strong majority of participants reported going out at night with groups of boys and girls, less than half had the experience of dating in groups or in pairs. Similarly, participants reported that their longest relationships averaged approximately 7 months, they had just over 1 serious relationship to date, they engaged in relatively low levels of sexual behavior, and just over a third had ever been deeply in love. Only $22 \%$ of the sample reported a current romantic relationship. In sum, while a large majority of participants had some experience in the romantic domain by age 15, high levels of engagement were relatively uncommon.

\section{Correlational Analyses}

As shown in Table 2, for the full cohort, early and contemporaneous peer and parent experiences tended to be negatively associated with indicators of intense engagement in the romantic domain. There were, nonetheless, several exceptions and caveats to this trend that should be noted: (a) a non-significant association between age 15 peer competence and number of serious romantic relationships, (b) the dating experience outcome was trivially correlated with early and contemporaneous maternal sensitivity and actually positively associated with both early and contemporaneous peer competence, and (c) correlations between early peer competence and romantic engagement, although statistically significant, were trivial to small in magnitude.

For the $20 \%$ of participants who reported being currently engaged in a romantic relationship, earlier and later peer and parent experiences were, with one exception, all significantly and non-trivially associated with the perceived quality of participants' romantic relationships at age 15 , such that higher quality parent and peer experiences were correlated positively with positive features of these relationships and negatively associated with negative features. The one exception to this trend was that concurrent maternal sensitivity was not significantly correlated with either positive or negative romantic relationship quality.

\section{Regression Analyses}

As indicated above, all four independent variables (i.e., earlier peer competence, contemporaneous peer competence, earlier parent-child quality, contemporaneous parent-child quality) were entered simultaneously into regressions as predictors of romantic engagement (dating experience, longest relationship, number of serious romantic relationships, sexual experience, and ever been deeply in love?) and measures of quality (positive, negative). (Note that a logistic regression was conducted for "Ever deeply in love" as this outcome variable was dichotomous). The robustness of significant effects was challenged by subsequently adding a set of four demographic variables to the regression analyses.

In general, earlier maternal sensitivity uniquely and negatively predicted indicators of depth of romantic engagement, although some of these effects were attenuated with the addition of demographic covariates (see Tables 3, 4). One partial exception to this general trend was the regressions predicting dating experience, with age 15 peer competence positively associated with the 
Table 2 Correlations among early and age 15 parent-child quality, early and age 15 peer competence, and indicators of romantic engagement and quality at age 15

\begin{tabular}{|c|c|c|c|c|c|c|c|c|c|c|c|}
\hline & \multicolumn{2}{|c|}{ Parent-child quality } & \multicolumn{2}{|c|}{ Peer competence } & \multicolumn{5}{|c|}{ Romantic engagement } & \multicolumn{2}{|c|}{ Romantic quality } \\
\hline & 1. Earlier & 2. Age 15 & 3. Earlier & 4. Age 15 & $\begin{array}{l}\text { 5. Dating } \\
\text { experience }\end{array}$ & 6. Longest & 7. \# Serious & 8. Sex & 9. In love $\mathrm{e}^{\mathrm{a}}$ & 10. Positive & 11. Negative \\
\hline 1. & - & & & & & & & & & & \\
\hline 2. & $\begin{array}{l}.42 * * * \\
(874)\end{array}$ & - & & & & & & & & & \\
\hline 3. & $\begin{array}{l}.39 * * * \\
(956)\end{array}$ & $\begin{array}{l}.23 * * * \\
(875)\end{array}$ & - & & & & & & & & \\
\hline 4. & $\begin{array}{l}.37 * * * \\
(937)\end{array}$ & $\begin{array}{l}.25 * * * \\
(866)\end{array}$ & $\begin{array}{l}.61 * * * \\
(938)\end{array}$ & - & & & & & & & \\
\hline 5. & $\begin{array}{l}.01 \\
(956)\end{array}$ & $\begin{array}{l}-.06 \\
(875)\end{array}$ & $\begin{array}{l}.08^{*} \\
(957)\end{array}$ & $\begin{array}{l}.16^{* * * *} \\
(938)\end{array}$ & - & & & & & & \\
\hline 6. & $\begin{array}{l}-.28 * * * \\
(827)\end{array}$ & $\begin{array}{l}-.15^{* * *} \\
(757)\end{array}$ & $\begin{array}{l}-.08^{*} \\
(828)\end{array}$ & $\begin{array}{l}-.11 * * \\
(812)\end{array}$ & $\begin{array}{l}.23 * * * \\
(828)\end{array}$ & - & & & & & \\
\hline 7. & $\begin{array}{l}-.17 * * * \\
(938)\end{array}$ & $\begin{array}{l}-.13 * * * \\
(857)\end{array}$ & $\begin{array}{l}-.08 * \\
(931)\end{array}$ & $\begin{array}{l}-.06 \\
(920)\end{array}$ & $\begin{array}{l}.30 * * * \\
(939)\end{array}$ & $\begin{array}{l}.31 * * * \\
(825)\end{array}$ & - & & & & \\
\hline 8 & $\begin{array}{l}-.19 * * * \\
(950)\end{array}$ & $\begin{array}{l}-.13 * * * \\
(869)\end{array}$ & $\begin{array}{l}-.09 * * \\
(951)\end{array}$ & $\begin{array}{l}-.12 * * * \\
(932)\end{array}$ & $\begin{array}{l}.16^{* * *} \\
(951)\end{array}$ & $\begin{array}{l}.25 * * * \\
(824)\end{array}$ & $\begin{array}{l}.34 * * * \\
(935)\end{array}$ & - & & & \\
\hline 9. & $\begin{array}{l}-.22 * * * \\
(942)\end{array}$ & $\begin{array}{l}-.17 * * * \\
(862)\end{array}$ & $\begin{array}{l}-.10 * * \\
(943)\end{array}$ & $\begin{array}{l}-.13 * * * \\
(924)\end{array}$ & $\begin{array}{l}.16^{* * *} \\
(943)\end{array}$ & $\begin{array}{l}.39 * * * \\
(820)\end{array}$ & $\begin{array}{l}.29 * * * \\
(929)\end{array}$ & $\begin{array}{l}.36 * * * \\
(938)\end{array}$ & - & & \\
\hline 10. & $\begin{array}{l}.15^{*} \\
(213)\end{array}$ & $\begin{array}{l}.07 \\
(194)\end{array}$ & $\begin{array}{l}.23 * * * \\
(213)\end{array}$ & $\begin{array}{l}.20 * * \\
(206)\end{array}$ & $\begin{array}{l}.22 * * \\
(213)\end{array}$ & $\begin{array}{l}.16^{*} \\
(205)\end{array}$ & $\begin{array}{l}.13 \\
(210)\end{array}$ & $\begin{array}{l}.14 * \\
(212)\end{array}$ & $\begin{array}{l}.39 * * * \\
(208)\end{array}$ & - & \\
\hline 11. & $\begin{array}{l}-.18^{*} \\
(212)\end{array}$ & $\begin{array}{l}-.02 \\
(193)\end{array}$ & $\begin{array}{l}-.27 * * * \\
(212)\end{array}$ & $\begin{array}{l}-.15^{*} \\
(205)\end{array}$ & $\begin{array}{l}-.16^{*} \\
(212)\end{array}$ & $\begin{array}{l}-.03 \\
(204)\end{array}$ & $\begin{array}{l}.07 \\
(210)\end{array}$ & $\begin{array}{l}.11 \\
(211)\end{array}$ & $\begin{array}{l}-.01 \\
(207)\end{array}$ & $\begin{array}{l}-.04 \\
(212)\end{array}$ & - \\
\hline
\end{tabular}

Note: ${ }^{a} 1=$ yes, $0=$ no. $* p<.05$, ** $p<.01$, *** $p<.001$ (two-tailed). $n$ s are in parentheses

outcome, even with demographic controls in place. Earlier peer competence was uniquely predictive of romantic quality (see Table 5, Model I). After adding demographic covariates (see Table 5, Model II), this effect remained for the prediction of positive but not negative quality. Earlier maternal sensitivity emerged as a significant predictor of positive quality in these more complex models. Note that the variables cumulatively accounted for modest proportions of the variance in each romantic outcome (3-8\% in Model I, which did not include demographic covariates and $6-13 \%$ in Model II equations, which did include these control variables).

\section{Discussion}

The results of this study were consistent both with evidence that adolescent romantic relationships reflect current and past relationship experiences with parents and peers (Furman et al. 1999) as well as the notion that the romantic domain may not be a salient developmental task of midadolescence (Roisman et al. 2004). Specifically, we found that high-quality experiences with parents and peers prior to and during adolescence tended to be negatively associated with indicators of intense engagement in this domain for the full NICHD SECCYD cohort, but positively associated with the reported quality of adolescents' romantic relationships at age 15 for the sub-set of adolescents engaged in them.

We resist the interpretation that evidence that peer and parent experiences were negatively correlated with indicators of romantic engagement is merely reflective of a kind of pseudo-intimacy that characterizes adolescents who engage in a relatively large number of relationships. Instead, given that supportive relationships with parents were associated with a wide range of indicators of intense romantic involvement, we are more inclined to interpret these findings as suggesting that serious engagement of this domain (either in terms of quantity of partners or depth of emotional investment) is less than optimal developmentally (Davies and Windle 2000; Neemann et al. 1995), perhaps in part because it is not until adulthood that intimacy in such relationships becomes a key challenge of development (Erikson 1968).

We should also note that, because the theoretical perspectives that framed this analysis do not claim that processes differ by males versus females, we did not present relevant moderator analyses. Nonetheless, 
Table 3 Linear regressions predicting engagement indicators at age 15

\begin{tabular}{|c|c|c|c|c|}
\hline & \multicolumn{4}{|c|}{ Romantic relationship engagement } \\
\hline & 1. Dating experience & 2. Longest relationship & 3. \# Serious relationships & 4. Sexual experience \\
\hline Model I & $(n=865)$ & $(n=747)$ & $(n=847)$ & $(n=859)$ \\
\hline Earlier maternal sensitivity & -.03 & $-.27 * * *$ & $-.14 * * *$ & $-.16 * * *$ \\
\hline Age 15 maternal sensitivity & $-.10 * *$ & -.02 & -.07 & -.05 \\
\hline Earlier peer competence & -.02 & .08 & -.02 & .01 \\
\hline Age 15 peer competence & $.23 * * *$ & -.06 & .03 & -.05 \\
\hline Model $R^{2}$ & $.04 * * *$ & $.08 * * *$ & $.03 * * *$ & $.04 * * *$ \\
\hline Model II & $(n=864)$ & $(n=746)$ & $(n=846)$ & $(n=858)$ \\
\hline Child sex & .01 & -.04 & $-.13 * * *$ & -.01 \\
\hline White/non-Hispanic? & -.03 & $-.09 *$ & $-.14 * * *$ & $-.08 *$ \\
\hline Maternal education & -.08 & $-.14 * *$ & -.04 & $-.09 *$ \\
\hline Income-to-needs (1 mo-age 15$)$ & .02 & $-.09 *$ & -.05 & -.05 \\
\hline Earlier maternal sensitivity & .01 & $-.13 * *$ & -.03 & -.07 \\
\hline Age 15 maternal sensitivity & $-.10 * *$ & -.02 & $-.08 *$ & -.05 \\
\hline Earlier peer competence & -.02 & $.11^{*}$ & .01 & .03 \\
\hline Age 15 peer competence & $.23 * * *$ & -.06 & .03 & -.05 \\
\hline Model $R^{2}$ & $.05 * * *$ & $.12 * * *$ & $.07 * * *$ & $.06 * * *$ \\
\hline
\end{tabular}

Coefficients are standardized betas

Note: $* p<.05 ; * * p<.01, * * * p<.001$

Table 4 Binary regressions predicting ever deeply in love at age 15

Romantic relationship engagement

1. Deeply in love M

\begin{tabular}{ll}
\hline Model I & $(n=852)$ \\
Earlier maternal sensitivity & $-.36(.09)^{* * *}$ \\
Age 15 maternal sensitivity & $-.20(.08)^{*}$ \\
Earlier peer competence & $.06(.10)$ \\
Age 15 peer competence & $-.08(.10)$ \\
Nagelkerke $R^{2}$ & $.07 * * *$ \\
Model II & $(n=851)$ \\
Child sex & $-.47(.16)^{* *}$ \\
White/non-Hispanic? & $-.43(.20)^{*}$ \\
Maternal education & $-.11(.04)^{* *}$ \\
Income-to-needs $(1$ mo-age 15$)$ & $-.11(.04)^{* *}$ \\
Earlier maternal sensitivity & $-.03(.11)$ \\
Age 15 maternal sensitivity & $-.20(.08)^{*}$ \\
Earlier peer competence & $.16(.10)$ \\
Age 15 peer competence & $.08(.10)$ \\
Nagelkerke $R^{2}$ & $.13 * * *$ \\
\hline
\end{tabular}

Unstandardized $B \mathrm{~s}$ and Standard Errors are provided because analyses are logistic regressions

Note: $* p<.05 ; * * p<.01, * * * p<.001$

supplementary analyses revealed no instance where a significant regression effect was moderated by sex. In addition, although our composites of earlier peer competence and maternal sensitivity aggregated data across a
Table 5 Linear regressions predicting quality indicators at age 15

\begin{tabular}{lcl}
\hline & \multicolumn{2}{c}{ Romantic relationship quality } \\
\cline { 2 - 3 } & $\begin{array}{l}\text { 1. Positive } \\
\text { quality }\end{array}$ & $\begin{array}{l}\text { 2. Negative } \\
\text { quality }\end{array}$ \\
\hline Model I & $(n=190)$ & $(n=189)$ \\
Earlier maternal sensitivity & .09 & -.09 \\
Age 15 maternal sensitivity & -.01 & .07 \\
Earlier peer competence & $.18^{*}$ & $-.19^{*}$ \\
Age 15 peer competence & .04 & -.05 \\
Model $R^{2}$ & $.06^{*}$ & $.07^{*}$ \\
Model II & $(n=190)$ & $(n=189)$ \\
Child sex & .00 & -.07 \\
White/non-Hispanic? & -.05 & $-.17^{*}$ \\
Maternal education & -.12 & .10 \\
Income-to-needs $(1$ mo-age 15$)$ & -.11 & -.04 \\
Earlier maternal sensitivity & $.20^{*}$ & -.04 \\
Age 15 maternal sensitivity & -.00 & .05 \\
Earlier peer competence & $.22^{*}$ & -.15 \\
Age 15 peer competence & .03 & -.06 \\
Model $R^{2}$ & $.09^{*}$ & $.10^{*}$ \\
\hline Coeffcients are standardied betas & &
\end{tabular}

Coefficients are standardized betas

Note: $* p<.05$

wide age range, in follow-up analyses we found no evidence that predictors assessed in infancy, preschool, or grade school were more or less strongly associated with the outcomes explored in this report. Also, it should be 
emphasized that analyses examining depth of engagement were based on the full NICHD SECCYD cohort, whereas the romantic quality questions explored in this study focused on the sub-set of participants currently in a (selfdefined) romantic relationship at age 15 . We do not present depth of engagement analyses for the romantically involved sub-group largely because indicators of depth of engagement are censored at the low end of the relationship quality distribution among such individuals. Indeed, not surprisingly, associations between early and later peer and parent experiences and depth of engagement indicators failed to emerge in supplementary analyses focused on the currently involved sub-sample.

The current study has a number of strengths. First, measures of peer, parent-child, and romantic relationships were drawn from a prospective, longitudinal study of development, resulting in evidence that experiences prior to adolescence were uniquely predictive of adolescent romantic relationship engagement and quality, above and beyond comparable contemporaneous assessments of parent and peer experience. Second, in no instance were associations between predictors and outcomes overestimated by the use of a single informant or measure, resulting in a relatively conservative test of our hypotheses. Finally, this study is among the first to distinguish among the origins of different parameters of functioning in adolescent romantic relationships (for an excellent theoretical taxonomy, see Collins 2003).

This research is nonetheless limited in several respects. Perhaps most critically, although rich information is available on participants in the NICHD SECCYD from infancy through adolescence, data specific to participants' romantic relationships are exclusively self-report. Arguably, information regarding involvement in the romantic domain (e.g., number of romantic partners, ever been deeply in love?) is best acquired from the adolescent him or herself. However, our assessment of relationship quality was also focused on the adolescents' perceptions of those experiences, an important though by no means comprehensive indicator of interpersonal functioning that is ideally complemented with observational and other measures. Additionally, it should be noted that social competence data for the current analysis derived exclusively from maternal-report, and the study, though multisite, is not based on a nationally representative sample.

The current analysis contributes to the literature in a number of respects. Specifically, results of this study support the notion that adolescents' romantic relationships reflect the relational history of those involved in them in mid-adolescence, both with parents and peers as assessed prospectively from infancy forward. In contrast, given evidence reported here and elsewhere that supportive early and later relationship experiences (particularly with parents) are normatively reflected in less intense engagement in the romantic domain in adolescence, it appears that adolescent romantic competence-at least by age 15-should not be regarded as a defining developmental task within which adaptation in adolescence is judged.

Open Access This article is distributed under the terms of the Creative Commons Attribution Noncommercial License which permits any noncommercial use, distribution, and reproduction in any medium, provided the original author(s) and source are credited.

\section{Appendix}

Current members of the Steering Committee of the NICHD Early Child Care Research Network, listed in alphabetical order, are: Jay Belsky (Birkbeck University of London), Cathryn Booth-LaForce (University of Washington), Robert H. Bradley (University of Arkansas at Little Rock), Celia A. Brownell (University of Pittsburgh), Margaret Burchinal (University of North Carolina, Chapel Hill), Susan B. Campbell (University of Pittsburgh), Elizabeth Cauffman (University of California, Irvine), Alison ClarkeStewart (University of California, Irvine), Martha Cox (University of North Carolina, Chapel Hill), Robert Crosnoe (University of Texas, Austin), James A. Griffin (NICHD Project Scientist and Scientific Coordinator), Bonnie Halpern-Felsher (University of California, San Francisco), Willard Hartup (University of Minnesota), Kathryn Hirsh-Pasek (Temple University), Daniel Keating (University of Michigan, Ann Arbor), Bonnie Knoke (RTI International), Tama Leventhal (Tufts University), Kathleen McCartney (Harvard University), Vonnie C. McLoyd (University of North Carolina, Chapel Hill), Fred Morrison (University of Michigan, Ann Arbor), Philip Nader (University of California, San Diego), Marion O'Brien (University of North Carolina, Greensboro), Margaret Tresch Owen (University of Texas, Dallas), Ross Parke (University of California, Riverside), Robert Pianta (University of Virginia), Kim M. Pierce (University of Wisconsin-Madison), A. Vijaya Rao (RTI International), Glenn I. Roisman (University of Illinois at UrbanaChampaign), Susan Spieker (University of Washington), Laurence Steinberg (Temple University), Elizabeth Susman (Pennsylvania State University), Deborah Lowe Vandell (University of California, Irvine), and Marsha Weinraub (Temple University).

\section{References}

Cohen, J. (1988). Statistical power analysis for the behavioral sciences (2nd ed.). New Jersey: Lawrence Erlbaum. 
Coley, R. L., \& Chase-Lansdale, P. L. (1998). Adolescent pregnancy and parenthood: Recent evidence and future directions. The American Psychologist, 53, 152-166. doi:10.1037/0003-066X. 53.2.152.

Collins, W. A. (2003). More than myth: The developmental significance of romantic relationships during adolescence. Journal of Research on Adolescence, 13, 1-24. doi:10.1111/1532-7795.1301001.

Collins, N. L., Cooper, M. L., Albino, A., \& Allard, L. (2002). Psychosocial vulnerability from adolescence to adulthood: A prospective study of attachment style differences in relationship functioning and partner choice. Journal of Personality, 70, 9651008.

Collins, W. A., \& Sroufe, L. A. (1999). Capacity for intimacy: A developmental construction. In W. Furman, B. B. Brown, \& C. Feiring (Eds.), The development of romantic relationships in adolescence (pp. 123-147). New York: Cambridge University Press.

Connolly, J. A., Furman, W., \& Konarski, R. (2000). The role of peers in the emergence of heterosexual romantic relationships in adolescence. Child Development, 71, 1395-1408. doi:10.1111/ 1467-8624.00235.

Connolly, J. A., \& Johnson, A. M. (1996). Adolescents' romantic relationships and the structure and quality of their close interpersonal ties. Personal Relationships, 3, 185-195. doi: 10.1111/j.1475-6811.1996.tb00111.x.

Davies, P. T., \& Windle, M. (2000). Middle adolescents' dating pathways and psychosocial adjustment. Merrill-Palmer Quarterly, 46, 90-118.

Ellis, B. J., Bates, J. E., Dodge, K. A., Fergusson, D. M., Horwood, J. L., Pettit, G. S., et al. (2003). Does father absence place daughters at special risk for early sexual activity and teenage pregnancy? Child Development, 74, 801-821. doi:10.1111/ 1467-8624.00569.

Engles, R. C. M. E., Finkenauer, C., Meeus, W., \& Deković, M. (2001). Parental attachment and adolescents' emotional adjustment: The associations with social skills and relational competence. Journal of Consulting Psychology, 48, 428-439.

Erikson, E. H. (1968). Identity, youth and crisis. New York: Norton.

Furman, W. (1996). The measurement of friendship perceptions: Conceptual and methodological issues. In W. M. Bukowski, A. F. Newcomb, \& W. W. Hartup (Eds.), The company they keep: Friendship in childhood and adolescence (pp. 41-65). New York: Cambridge University Press.

Furman, W. (1999). Friends and lovers: The role of peer relationships in adolescent heterosexual romantic relationships. In W. A. Collins \& B. Laursen (Eds.), Relationships as developmental contexts: Minnesota Symposium on Child Psychology (Vol. 30, pp. 133-154). Hillsdale: Erlbaum.

Furman, W., Brown, B. B., \& Feiring, C. (1999). The development of romantic relationships in adolescence. New York: Cambridge University Press.

Furman, W., Simon, V. A., Shaffer, L., \& Bouchey, H. A. (2002). Adolescents' working models and styles for relationships with parents, friends, and romantic partners. Child Development, 73, 241-255. doi:10.1111/1467-8624.00403.

Furman, W., \& Wehner, E. A. (1994). Romantic views: Toward a theory of adolescent romantic relationships. In R. Montemayor, G. R. Adams, \& G. P. Gullota (Eds.), Advances in adolescent development: Relationships during adolescence (Vol. 6, pp. 168-175). Thousand Oaks: Sage.

Gresham, F. M., \& Elliott, S. N. (1990). The social skills rating system. Circle Pines: American Guidance Service.

Hazan, C., \& Shaver, P. (1987). Romantic love conceptualized as an attachment process. Journal of Personality and Social Psychology, 52, 511-524. doi:10.1037/0022-3514.52.3.511.
Kim, H. K., \& Capaldi, D. M. (2004). The association of antisocial behavior and depressive symptoms between partners and risk for aggression in romantic relationships. Journal of Family Psychology, 18, 82-96. doi:10.1037/0893-3200.18.1.82.

Neemann, J., Hubbard, J., \& Masten, A. S. (1995). The changing importance of romantic relationship involvement to competence from late childhood to late adolescence. Development and Psychopathology, 7, 727-750.

NICHD Early Child Care Research Network. (1998). Early child care and self-control, compliance and problem behavior at 24 and 36 months. Child Development, 69, 1145-1170.

NICHD Early Child Care Research Network. (2002). Early child care and children's development prior to school entry: Results from the NICHD Study of Early Child Care and Youth Development. American Educational Research Journal, 39, 133-164. doi: 10.3102/00028312039001133.

NICHD Early Child Care Research Network. (2005). Child care and child development: Results from the NICHD Study of Early Child Care and Youth Development. New York: The Guilford Press.

Roisman, G. I., Collins, W. A., Sroufe, L. A., \& Egeland, B. (2005). Predictors of young adults' representations of and behavior in their current romantic relationship: Prospective tests of the prototype hypothesis. Attachment \& Human Development, 7, 105-121. doi:10.1080/14616730500134928.

Roisman, G. I., Madsen, S. D., Hennighausen, K. H., Sroufe, L. A., \& Collins, W. A. (2001). The coherence of dyadic behavior across parent-child and romantic relationships as mediated by the internalized representation of experience. Attachment \& Human Development, 3, 156-172. doi:10.1080/14616730110056946.

Roisman, G. I., Masten, A. S., Coatsworth, J. D., \& Tellegen, A. (2004). Salient and emerging developmental tasks in the transition to adulthood. Child Development, 75, 123-133. doi: 10.1111/j.1467-8624.2004.00658.x.

Scharf, M., \& Mayseless, O. (2001). The capacity for romantic intimacy: Exploring the contribution of best friend and marital and parental relationships. Journal of Adolescence, 24, 379-399. doi:10.1006/jado.2001.0405.

Shulman, S., Levy-Shiff, R., Kedem, P., \& Alon, E. (1997). Intimate relationships among adolescent romantic partners and same-sex friends: Individual and systemic perspectives. In S. Shulman \& W. A. Collins (Eds.), Romantic relationships in adolescence: Developmental perspectives. New directions for child development, No. 78 (pp. 37-51). San Francisco: Jossey-Bass/Pfeiffer.

Sullivan, H. S. (1953). The interpersonal theory of psychiatry. New York: Norton.

\section{Author Biographies}

Glenn I. Roisman received his Ph.D. from the Institute of Child Development at the University of Minnesota in 2002. He is now an associate professor in the developmental division of the Department of Psychology at the University of Illinois at Urbana-Champaign, USA. Dr. Roisman's scholarly interests concern the legacy of childhood experience as an organizing force in adolescent and adult development. Recently, Dr. Roisman was honored for this work with a 2007 Award for Early Research Contributions from the Society for Research in Child Development.

Cathryn Booth-LaForce is the Charles and Gerda Spence Professor and Executive Associate Dean of the School of Nursing at the University of Washington. She is a Professor of Family \& Child Nursing and a Adjunct Professor of Psychology. Dr. Booth-LaForce's scholarly interests include attachment, social functioning, and friendship from early childhood through adolescence. 
Elizabeth Cauffman is an Associate Professor in the Department of Psychology and Social Behavior at the University of California, Irvine. The primary theme across all her research is adolescent development, mental health, and juvenile justice, with a special emphasis on female offenders. Specifically, she is examining the developmental trajectories of adolescent offenders as well as their mental health issues and treatment needs.
Susan J. Spieker received her Ph.D. from Cornell University's Human Development and Family Studies in 1982. She is Professor of Nursing and Director of the Center on Infant Mental Health and Development at the University of Washington. Dr. Spieker's research interests focus on interventions to promote positive infant-parent relationships and prevention of problem behaviors in the toddler and preschool years. 